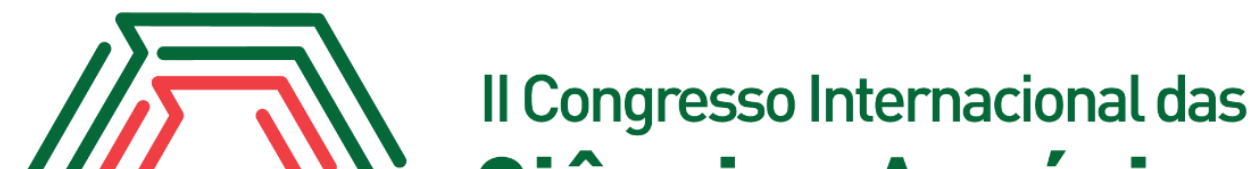 Ciências Agrárias COINTER - PDVAgro 2017
}

\section{TESTE DE VIGOR EM SEMENTES DE CEBOLA}

\begin{abstract}
Apresentação: Pôster
Jacquelinne Alves de Medeiros Araújo ${ }^{1}$; Joabe Freitas Crispim²; Antônio Gideilson Correia da Silva ${ }^{3}$; José Elinaldo Alves Bento ${ }^{4}$; Jailma Suerda Silva de Lima ${ }^{5}$
\end{abstract}

\section{Introdução}

A utilização de sementes de alta qualidade é fundamental para o estabelecimento de populações adequadas em campo, o que influencia na produtividade das culturas, garantindo assim, produtos de alta qualidade comercial (RAMOS et al, 2014; ARAUJO et al, 2011). Para uma análise completa da qualidade de sementes, há necessidade de se complementar as informações fornecidas pelo teste de germinação com testes de vigor, os quais possibilitam selecionar os melhores lotes para comercialização (DIAS et al., 2006; ARAUJO et al, 2011). Dentro deste contexto, a utilização de métodos rápidos, confiáveis e de fácil execução é fundamental para a avaliação do potencial fisiológico das sementes, por agilizar as tomadas de decisões referentes ao manejo dos lotes (DIAS et al., 2006), como é o caso do teste de envelhecimento acelerado.

Apesar de diversos trabalhos terem mostrado a eficiência do teste de envelhecimento acelerado em sementes de hortaliças, como em pimentão (RODO et al., 2000) e pepino (BHERING et al., 2000), para sementes de cebola esses trabalhos ainda são escassos, especialmente quanto à determinação da temperatura e tempo de exposição à esse teste. Logo, pesquisas nesse sentido, principalmente com sementes de cebola, fazem-se necessárias, pois condições muito drásticas ou brandas podem dificultar ou impedir a detecção de diferenças de qualidade entre os lotes (SPINOLA et.al, 1998; MARCOS FILHO, 1999).

\footnotetext{
${ }^{1}$ Agronomia, UFERSA, jacquelinne87@hotmail.com

${ }^{2}$ Agronomia, UFERSA, crispinjoabef@gmail.com

${ }^{3}$ Agronomia, UFERSA, antoniogideilson@hotmail.com

${ }^{4}$ Agronomia, UFERSA, elinaldoalves.lavras@gmail.com

${ }^{5}$ Doutora, UFERSA, jailmaagro@gmail.com
} 
Diante do exposto, este presente trabalho tem por objetivo avaliar sementes de cebola em situação de estresse de temperaturas através do teste de envelhecimento em diferentes tempos de exposição.

\section{Fundamentação Teórica}

A qualidade de um lote de sementes compreende uma série de características ou de atributos que determinam o seu valor para a semeadura, os quais são considerados como de natureza genética, física, fisiológica e sanitária, com destaque para o potencial fisiológico, que é diretamente responsável pelo desempenho das sementes em campo e armazenamento (RODO et al., 2000).

A qualidade fisiológica das sementes de hortaliças é rotineiramente avaliada pelo teste de germinação, realizado a partir da determinação da proporção de sementes capazes de produzir plântulas normais sob condições favoráveis de temperatura, luz, umidade, aeração e substrato (BEWLEY E BLACK, 1994). Entretanto, este teste apresenta limitações, principalmente quanto à diferenciação de lotes e à discrepância dos resultados em relação à emergência das plântulas em campo, tornando-se importante, portanto, que informações mais detalhadas sobre a qualidade das sementes sejam obtidas em complementação às fornecidas pelo teste de germinação através da realização de testes de vigor (ATAIDE et al., 2012). Informações relativas ao vigor das sementes são extremamente importantes, pois frequentemente, observa-se que lotes de sementes apresentando germinação semelhante exibem comportamentos distintos no campo e/ou armazenamento (BHERING et.al, 2000).

\section{Metodologia}

O trabalho foi realizado no Laboratório de Análise de Sementes (LAS) da Universidade Federal Rural do Semi-Árido (UFERSA), Mossoró-RN. Conduzido em um delineamento inteiramente casualizado, utilizando três lotes de sementes de cebola (lote 1: 032525; lote 2030462; lote 3: 026970) cultivar IPA 11. Foram realizadas as seguintes análises: Grau de umidade; Teste de germinação; Primeira contagem; e Envelhecimento acelerado.

Grau de umidade: realizada pelo método da estufa à $105 \pm 3^{\circ} \mathrm{C}$, durante 24 horas, conforme as Regras para Análise de Sementes - RAS (Brasil, 1992); Teste de germinação: conduzido a $20^{\circ} \mathrm{C}$, utilizando papel mata-borrão em caixas de plástico do tipo gerbox, com quatro repetições de 50 
sementes, realizado durante 12 dias, conforme as Regras para Análise de Sementes (Brasil, 1992); Primeira contagem: efetuado em conjunto com o teste de germinação, determinando-se a porcentagem de plântulas normais no sexto dia, após a sua instalação (Brasil, 1992); Envelhecimento acelerado: foram utilizadas 250 sementes por lote, distribuidas sobre bandejas de tela de alumínio, fixadas no interior das caixas de plástico tipo gerbox, adicionados $40 \mathrm{~mL}$ de água destilada em cada caixa, submetidos a $38^{\circ} \mathrm{C}, 42^{\circ} \mathrm{C}$ e $46^{\circ} \mathrm{C}$, mantidas em estufas do tipo BOD, por um período de 48,72 e 96 horas após a instalação. Decorrido estes períodos foram colocadas para germinar em quatro repetições de 50 sementes, em papel mata-borrão em caixas de plástico tipo gerbox, em temperatura de $20^{\circ} \mathrm{C}$. A avaliação das plântulas foi realizada seis dias após a semeadura, obtendo a primeira contagem de germinação.

Os dados obtidos foram submetidos à análise de variância utilizando o software estatístico SISVAR (FERREIRA, 2000), e aplicado o teste Tukey a 5\% utilizado para comparar as médias dos dados.

\section{Resultados e Discussões}

Os resultados da Tabela 1 mostram que o teste de germinação (G\% e PC\%) não promoveu diferença significativa entre os lotes analisados.

TABELA 1 - Resultados do teste de Germinação (G\%); Primeira contagem (PC\%); e primeira contagem obtida pelo teste de Envelhecimento Acelerado realizado sob efeito de temperaturas $\left(38 ; 42\right.$ e $\left.46^{\circ} \mathrm{C}\right)$ e períodos de exposição (48; 72 e 96h) obtidos em três lotes de sementes de cebola, cultivar IPA 11. Fonte: Própria

\begin{tabular}{|c|c|c|c|c|c|c|c|c|c|c|c|c|}
\hline \multirow{3}{*}{ Lote } & \multirow{3}{*}{ GU } & \multirow{3}{*}{$\mathrm{G} \%$} & \multirow{3}{*}{$\mathrm{PC}(\%)$} & \multicolumn{9}{|c|}{ PC (\%) Após o Envelhecimento Acelerado } \\
\hline & & & & \multicolumn{3}{|c|}{$38^{\circ} \mathrm{C}$} & \multicolumn{3}{|c|}{$42^{\circ} \mathrm{C}$} & \multicolumn{3}{|c|}{$46^{\circ} \mathrm{C}$} \\
\hline & & & & $48 \mathrm{~h}$ & $72 \mathrm{~h}$ & $96 \mathrm{~h}$ & $48 \mathrm{~h}$ & $72 \mathrm{~h}$ & $96 \mathrm{~h}$ & $48 \mathrm{~h}$ & $72 \mathrm{~h}$ & $96 h$ \\
\hline 1 & 12,59 & $99 \mathrm{a}$ & $96 \mathrm{a}$ & $97 \mathrm{a}$ & $84 \mathrm{a}$ & $85 \mathrm{ab}$ & $85 \mathrm{a}$ & $65 \mathrm{a}$ & $63 \mathrm{a}$ & $15 \mathrm{a}$ & $1 \mathrm{a}$ & $4 \mathrm{c}$ \\
\hline 2 & 10,99 & $95 \mathrm{a}$ & $82 \mathrm{a}$ & $84 \mathrm{~b}$ & $68 \mathrm{~b}$ & $74 \mathrm{~b}$ & $77 \mathrm{a}$ & $61 \mathrm{a}$ & $64 \mathrm{a}$ & $16 \mathrm{a}$ & $4 \mathrm{a}$ & $44 \mathrm{a}$ \\
\hline 3 & 13,33 & $99 \mathrm{a}$ & $98 \mathrm{a}$ & $97 \mathrm{a}$ & $91 \mathrm{a}$ & $93 \mathrm{a}$ & $82 \mathrm{a}$ & $72 \mathrm{a}$ & $73 a$ & $24 \mathrm{a}$ & $10 \mathrm{a}$ & $33 \mathrm{~b}$ \\
\hline $\mathrm{CV}(\%)$ & - & 1,99 & 3,55 & 3,56 & 8,24 & 8,32 & 8,09 & 16,60 & 8,95 & 44,1 & 9,57 & 15,6 \\
\hline
\end{tabular}

* Médias seguidas pela mesma letra, na coluna, não diferem pelo teste de Tukey a 5\%.

Resultados obtidos também por Dias et al (2006) verificaram que o teste de germinação não apresentou diferença significativa entre os lotes de sementes de cebola analisados, indicando assim a limitação desse teste quanto à diferenciação do vigor de lotes de sementes de cebola.

Já em relação aos resultados obtidos quando realizado o teste de envelhecimento acelerado (Tabela 1), pode-se observar que apenas quando realizado à $38^{\circ} \mathrm{C}$, nos três períodos de exposição ao 
teste, houve diferença significativa entre os lotes de sementes analisados, sendo os Lotes 1 e 3 superiores ao Lote 2. Sendo, portanto, essa temperatura a que se mostrou mais eficiente na avaliação do teste de vigor das sementes de cebola. Resultados semelhantes ao observado por Bhering et al (2006), no qual verificaram que o teste de envelhecimento acelerado quando conduzido a $38^{\circ} \mathrm{C}$, tanto pelo método tradicional como pelo método modificado (uso de solução salina), mostrou-se eficiente na avaliação do vigor das sementes de pimenta, já que forneceu dados semelhantes aos obtidas na primeira contagem de germinação e ao teste de germinação.

Pode-se observar ainda que quando as sementes foram submetidas à $46^{\circ} \mathrm{C}$, independente do período de exposição, houve uma diminuição brusca na germinação dessas sementes em todos os lotes avaliados, o que pode estar relacionado ao estresse ocasionado nas sementes em decorrência da temperatura elevada, já que temperaturas acima de $40^{\circ} \mathrm{C}$ causam a desnaturação de proteínas, tanto estruturais quanto aquelas que atuam como enzimas, acarretando em alterações na degradação e mobilização das reservas armazenadas nas sementes, resultando na redução da energia disponível para a germinação (DOTTO E SILVA, 2017).

\section{Conclusões}

1. O teste de germinação não apresentou diferenciação dos lotes de sementes de cebola analisados;

2. O teste de envelhecimento acelerado quando realizado à $38^{\circ} \mathrm{C}$, nos três períodos de exposição, apresentou diferenciação entre os lotes de sementes analisados, sendo os Lotes 1 e 3 superiores ao Lote 2 , sendo essa a temperatura de exposição mais adequada à essas sementes.

\section{Referências}

ARAUJO, R. F.; ZONTA, J. B.; ARAUJO, E. F.; HEBERLE, E.; ZONTA, F. M. G. Teste de condutividade elétrica para sementes de feijão-mungo-verde. Revista Brasileira de Sementes, v. 33, n.1, p. 123-130, 2011.

ATAIDE, G. M.; FLÔRES, A. V.; BORGES, E. E. L.; RESENDE, R. T. Adequação da metodologia do teste de condutividade elétrica para sementes de Pterogyne nitens Tull. Revista Brasileira de Ciências Agrárias, Recife, v. 7, n. 4, p. 635-640, 2012.

BEWLEY, J. D.; BLACK, M. Seeds: physiology of development and germination. 2. ed. New York: Plenum Press, 455 p., 1994. 
BHERING, M.C.; DIAS, D.C.F.S.; GOMES, J.M.; BARROS, D.I. Métodos para avaliação do vigor de sementes de pepino. Revista Brasileira de Sementes, Londrina, v.22, n.2, p.171-175, 2000.

BHERING, M C.; DIAS, D. C. F S.; VIDIGAL, D. S.; NAVEIRA, D. S; P. Teste de envelhecimento acelerado em sementes de pimenta. Revista Brasileira de Sementes, v. 28, n. 3, p. 64-71, 2006.

BRASIL. Ministério da Agricultura e Reforma Agrária. Regras para análise de sementes. Brasília, 365p., 1992.

DIAS, D.C.F.S.; BHERING, M.C.; TOKUHISA, D.; HILST, P.C. Teste de condutividade elétrica para avaliação do vigor de sementes de cebola. Revista Brasileira de Sementes, vol. 28, $\mathrm{n}^{\circ}$ 1, p.154$162,2006$.

DOTTO, L.; SILVA, V. N. Envelhecimento acelerado para avaliação do vigor de sementes de Parapiptadenia rígida. Agrarian Academy, Centro Científico Conhecer - Goiânia, v. 4, n. 7, p. 218226, 2017.

FERREIRA, D.F. Sistema de análises de variância para dados balanceados. Lavras: UFLA, 2000. (SISVAR 4.1, pacote computacional).

MARCOS FILHO, J. Teste de envelhecimento acelerado. In: KRZYZANOWSKI, F.C.; VIEIRA, R.D.; FRANÇA-NETO, J.B. (Ed.). Vigor de sementes: conceitos e testes. Londrina: ABRATES, cap.3, p.1-24, 1999.

RAMOS, H. M. M.; BASTOS, E. A.; CARDOSO, M. J.; RIBIRO, V. Q.; NASCIMENTO, F. N. Produtividade de grãos verdes do feijão-caupi sob diferentes regimes hídricos. Revista Engenharia Agrícola, Jaboticabal, v. 34, n. 4, p. 683-694, 2014.

RODO, A. B.; PANOBIANCO, M; FILHO, J. M.; Metodologia alternativa do teste de envelhecimento acelerado para sementes de cenoura. Scientia Agricola, v.57, n.2, p.289-292, 2000.

SPINOLA, M.C.M.; CALIARI, M.F.; MARTINS, L.; TESSARIOLI NETO, J. Comparação entre métodos para avaliação do vigor de sementes de cenoura. Revista Brasileira de Sementes, Brasília, v.20, n.2, p.301-305, 1998. 